\title{
Role Of Rfid To Minimize Reverse Logistics: A Case Study Perspective
}

\author{
Tanvi Agrawal1, Sachin Modgil2, Vishal Singh Patyal3, K.Maddulety4, \\ P.K.Biswas5 \\ ${ }^{12345}$ (National Institute of Industrial Engineering, Vihar Lake, Mumbai, India)
}

\begin{abstract}
Reverse logistics is considered as a part of supply chain and can be minimized in the form of complaints received to strengthen the whole supply chain. Henceforth this paper attempts to analyze the gaps between identified defects and complaints received in ongoing production process through statistical analysis, which can be utilized further to minimize. A case study from a chemical industry has been considered to reflect this gap. Additionally author has made an attempt to explain the impact and efficacy of RFID for minimizing the reverse logistics part (received complaints) in the form of proposed algorithm. This algorithm may help further to monitor manufacturing process at various stages, for real time information extraction in RFID implementation scenario. This customer complaint handling system through RFID may provide an opportunity to managers in taking decision for analyzing the customer specific cause and effect relationship between product failure and process optimization. This algorithm can be customized further to meet the needs of other production packaging and packing processes whenever the specifications are not in line.
\end{abstract}

Keywords - Customer complaint, RFID (Radio Frequency Identification), Reverse Logistics.

\section{Introduction}

Measuring and handling of customer complaints are crucial for any business survival and each firm needs to have focused strategy to reduce customer complaints in order to create and retain customers. Complaint treatment can be defined as: "...A process that addresses issues that concern customers..." [1].To handle a complaint with speed and effectiveness is a part of the responsiveness [2]. The reverse logistics play important role in customer complaint handling. The reverse logistics concept goes hand in hand with the product supply chain of a firm. The customer satisfaction depends upon the fact that how effective reverse logistics of a firm is, because the cost of creating a customer is three times, than retaining a customer [3]. Other researchers favored that cost of losing a customer usually far exceeds the expenses of retaining the same customer [4]. The reverse logistics is not exactly the reverse of logistics, but both differ from each other in various aspects viz. quantity of dispatch, item type (category), cycle time, schedule and path of distribution. These various aspects are uncertain in reverse logistics [5].

In reverse logistics the product moves from customer or distributor/wholesaler to the manufacturer. In this whole journey there are some loss of product value, packaging and packing as well, while some time the products lose their function also during reverse logistics [6].

There are number of factors associated with reverse logistics and how the return process of finished products takes place with respect to cost benefit analysis [7]. The need of reverse logistics can be for the purpose of recycling, customer complaint handling, buy back contract, market returned products. The reverse flow or role of reverse channels for customer complaint handling/satisfaction related to recycling play a crucial role [8].The reverse logistics can be defined as activities involved in finished product returns, recycling, reuse, disposal, remanufacturing or repair of products [9].In the above mentioned processes of reverse logistics return of finished products takes place due to defects ignorance internally in the manufacturing process which leads to loss of profit margin. Solution to resolve this issue is to detect defects while the process is taking place during manufacturing, by using the real time information of the process for specifications limit check. The solution for process improvement through RFID technology implementation for cost reduction in supply chain management [10]. Here authors have considered customer complaint of a product as one of the reverse logistics process, because the product starts from customer and reach to manufacturer for complaint resolution [11]. In this paper a statistical analysis has been done showing the gap between the defects detected and complaints received through chemical industry case study, thereafter a solution in the form of algorithm for RFID implementation with the help of MATLAB 7.0.

The 2nd section includes literature review of reverse logistics and RFID importance, $3^{\text {rd }}$ section includes the case study, $4^{\text {th }}$ section includes proposed algorithm, $5^{\text {th }}$ section explains the performance Analysis while $6^{\text {th }}$ follows conclusion lastly $7^{\text {th }}$ includes limitations and future scope. 
Role of RFID to minimize reverse logistics: A case study perspective

\section{Literature Review}

Reverse logistics administered growing attention from equally among the academic world and industries in recent years until last decade .Paralleled with its counterpart, forward logistics, research in reverse logistics is still in its early stages [12].

Reverse logistics is defined as '...the process of planning, implementing and controlling backward flows of raw materials, in process inventory, packaging and finished goods, from a manufacturing, distribution or use point, to a point of recovery or point of proper disposal....'.[13].Reverse logistics embraces the movement in the reverse direction. With the cumulative environment awareness and the necessity for sustainable development, customers are more alert of the green items in products than earlier. Organizations are trying to remanufacture and recycle end-of-life or reimbursed products in order to minimize the negative influence on environment [14].

There are three reasons why organizations are opting for reverse logistics first one is the increasing prominence of environmental concerns and their influence on society [15][16][13], second one is benefits that the organization gains by refining their return methods \& procedures such as image enhancement, improved efficiency and effectiveness in management of returned materials, which helps in achieving new profits levels [17][18][13], the third one is a new and growing environmental regulations [18][13].Therefore proactive approach in reverse logistics is needed because the organizations are currently operating in highly complex, dynamic and competitive environment. Further there are three transaction points in flow of reverse logistics viz. Point of Sale (POS), Point of Return POR) and Point of Exit (POE). POS is the place at which it is easy for providers to distribute products to consumers, POE is the end node of a logistics network while POR is the place at which customers can dispose or return used products [19]. Most of the researchers deployed forecasting and simulation techniques only for real-time information extraction to resolve the issue at any of these points. As forecast are not at all times similar to real situation. Therefore real-time data collection is desirable to endorse the amount of returned products. RFID technologies can increase accuracy and speed of processes for increasing the efficiency and reorganization of the systems [20]. RFID gives optimized solution for various logistics problems [19]. Hence, RFID should be applied in reverse logistics as this technology provides a real-time communication with numerous objects at the same time at a distance, without contact or direct line of sight reflecting the quantity collected in collection points [21][22].RFID tags assists in identifying the type of collected products by fixing RFID readers at various collection points.

\section{Case Study analysis}

The case study discussed in this paper is about customer complaints of a chemical plant. The customer complaints are pertaining to chemical A, which find its applications in Textile, Polymer and Pharmaceutical industry as de-coloring agent. The chemical A is produced in highly controlled environment and is having critical specification requirements from customers. Large numbers of customer complaints were received during 2001- 11. Author has made an attempt to identify the causes, why and how these probable reasons for customer complaints can prevail over and monitored on real time basis. Assuming that the input parameters are being checked by RFID fixed readers implemented at different check points and tags are affixed at each testing instrument for testing the specification parameters like purity, bulk density of powder, particle size etc. and also at the packing of Drum, Bucket, Carboy and Bags. Accordingly the input parameters are checked according to the specified range form of different entries of input parameters for algorithm in software

The chemical A is produced in bulk and packed in four packing's viz. (1) drums (D) of $50 \mathrm{~kg}$ packing having batch size of 222 drums (2) bucket (Bu) of $25 \mathrm{~kg}$ packing having batch size of 400 buckets (3) Carboy (C) of $50 \mathrm{~kg}$ packing having batch size of 250 carboys and, (4) bags (B) of $20 \mathrm{~kg}$ packing of batch size 800 bags. Author has considered the number of defects detected and the actual customer complaints received in process quality assurance through statistical analysis at $95 \%$ confidence level for above mentioned packing(s).

The data used for analysis purpose and the parameters used to judge product status is shown in the Table -2. This is based on the company data base for the period of 2001-2011 for defects detected as well as complaints received for comparative analysis. For convenience author has divided the complaints in four categories viz. quality based, packing \& packaging based, specification based and application based complaints.

Table -2 shows data related to defects detected during online inspection which might result in critical customer complaints in future. 
Role of RFID to minimize reverse logistics: A case study perspective

Table 2 Defects detected during manufacturing and packaging process

\begin{tabular}{|l|l|l|l|l|l|l|l|l|l|l|l|l|l|l|l|l|}
\hline Year & \multicolumn{10}{c|}{ Defects (may lead to complain) Detected } \\
\hline & \multicolumn{10}{|c|}{ Quality Based } & \multicolumn{1}{c|}{ Packing based } & \multicolumn{3}{|c|}{ Specification based } & \multicolumn{5}{c|}{ Application based } \\
\hline & D & Bu & C & B & D & Bu & C & B & D & Bu & C & B & D & Bu & C & B \\
\hline $\mathbf{2 0 0 1}$ & 0 & 0 & 1 & 0 & 0 & 2 & 1 & 0 & 1 & 0 & 4 & 0 & 2 & 3 & 1 & 0 \\
\hline $\mathbf{2 0 0 2}$ & 4 & 3 & 1 & 0 & 3 & 1 & 2 & 0 & 1 & 0 & 2 & 0 & 1 & 2 & 6 & 0 \\
\hline $\mathbf{2 0 0 3}$ & 1 & 2 & 1 & 4 & 1 & 0 & 0 & 8 & 2 & 0 & 1 & 6 & 1 & 2 & 1 & 0 \\
\hline $\mathbf{2 0 0 4}$ & 0 & 2 & 2 & 1 & 0 & 2 & 1 & 3 & 1 & 0 & 2 & 1 & 0 & 2 & 0 & 1 \\
\hline $\mathbf{2 0 0 5}$ & 1 & 1 & 1 & 0 & 2 & 1 & 0 & 2 & 1 & 2 & 3 & 6 & 0 & 1 & 2 & 1 \\
\hline $\mathbf{2 0 0 6}$ & 1 & 0 & 1 & 1 & 2 & 1 & 0 & 1 & 2 & 1 & 1 & 1 & 0 & 0 & 0 & 1 \\
\hline $\mathbf{2 0 0 7}$ & 1 & 2 & 0 & 0 & 0 & 1 & 3 & 2 & 1 & 0 & 1 & 2 & 0 & 0 & 1 & 0 \\
\hline $\mathbf{2 0 0 8}$ & 0 & 0 & 1 & 0 & 3 & 2 & 1 & 8 & 0 & 3 & 2 & 1 & 0 & 0 & 2 & 1 \\
\hline $\mathbf{2 0 0 9}$ & 2 & 1 & 0 & 2 & 1 & 3 & 2 & 3 & 1 & 1 & 2 & 3 & 0 & 1 & 2 & 0 \\
\hline $\mathbf{2 0 1 0}$ & 1 & 2 & 0 & 1 & 2 & 0 & 1 & 1 & 3 & 1 & 2 & 5 & 0 & 0 & 2 & 2 \\
\hline $\mathbf{2 0 1 1}$ & 1 & 1 & 1 & 0 & 1 & 2 & 2 & 1 & 0 & 0 & 0 & 1 & 0 & 1 & 2 & 0 \\
\hline
\end{tabular}

${ }^{*} \mathrm{D}=$ Drums, ${ }^{*} \mathrm{Bu}=\mathrm{Buckets},{ }^{*} \mathrm{C}=\mathrm{Carboy},{ }^{*} \mathrm{~B}=\mathrm{Bags}$

Table -3 shown below is the data of customer complaints received during the period of 2001 to 2011 for various types viz. quality based, packing \& packaging based, specification based and application based complaints.

Table 3 Complaints received from customers

\begin{tabular}{|l|l|l|l|l|l|l|l|l|l|l|l|l|l|l|l|l|}
\hline Year & \multicolumn{11}{c|}{ Complaints received } \\
\hline & \multicolumn{11}{|c|}{ Quality Based } & \multicolumn{10}{c|}{ Packing based } & \multicolumn{1}{|c|}{ Specification based } & \multicolumn{3}{|c|}{ Application based } \\
\hline & D & Bu & C & B & D & Bu & C & B & D & Bu & C & B & D & Bu & C & B \\
\hline $\mathbf{2 0 0 1}$ & 2 & 1 & 2 & 0 & 0 & 3 & 3 & 0 & 0 & 1 & 3 & 0 & 4 & 5 & 2 & 0 \\
\hline $\mathbf{2 0 0 2}$ & 1 & 4 & 3 & 0 & 2 & 0 & 1 & 0 & 1 & 0 & 1 & 0 & 2 & 4 & 5 & 0 \\
\hline $\mathbf{2 0 0 3}$ & 0 & 2 & 1 & 7 & 1 & 0 & 0 & 12 & 1 & 0 & 1 & 4 & 3 & 6 & 2 & 2 \\
\hline $\mathbf{2 0 0 4}$ & 3 & 1 & 2 & 5 & 0 & 4 & 2 & 8 & 1 & 1 & 3 & 3 & 2 & 4 & 0 & 2 \\
\hline $\mathbf{2 0 0 5}$ & 2 & 0 & 4 & 2 & 3 & 1 & 1 & 5 & 0 & 1 & 2 & 3 & 1 & 2 & 3 & 1 \\
\hline $\mathbf{2 0 0 6}$ & 1 & 1 & 1 & 1 & 2 & 3 & 0 & 1 & 0 & 0 & 0 & 4 & 1 & 1 & 0 & 2 \\
\hline $\mathbf{2 0 0 7}$ & 1 & 2 & 2 & 0 & 1 & 1 & 2 & 4 & 0 & 0 & 1 & 2 & 0 & 0 & 2 & 1 \\
\hline $\mathbf{2 0 0 8}$ & 1 & 1 & 7 & 2 & 1 & 1 & 0 & 6 & 1 & 2 & 1 & 2 & 0 & 0 & 0 & 0 \\
\hline $\mathbf{2 0 0 9}$ & 3 & 3 & 1 & 3 & 1 & 1 & 2 & 4 & 0 & 0 & 0 & 1 & 2 & 2 & 1 & 0 \\
\hline $\mathbf{2 0 1 0}$ & 1 & 2 & 3 & 1 & 1 & 0 & 0 & 2 & 1 & 1 & 1 & 2 & 0 & 0 & 1 & 1 \\
\hline $\mathbf{2 0 1 1}$ & 2 & 4 & 2 & 1 & 0 & 1 & 1 & 1 & 0 & 0 & 0 & 1 & 0 & 0 & 2 & 0 \\
\hline
\end{tabular}

${ }^{*} \mathrm{D}=$ Drums, ${ }^{*} \mathrm{Bu}=$ Buckets, ${ }^{*} \mathrm{C}=$ Carboy, ${ }^{*} \mathrm{~B}=$ Bags

Table-4 shows various parameters for monitoring quality based parameter ranges from $84-87 \%$ (percentage of purity) and $88-92 \%$ (percentage of purity), otherwise product is not fit for customer. $2^{\text {nd }}$ parameter is based on

application, which is 4 - 6 micron (particle size), otherwise product is not fit for customer. $3^{\text {rd }}$ parameter is specification based ' $\mathrm{pH}$ ' (ranges 6 to 10 ) and bulk density (ranges from $1.4-1.6$ ). $4^{\text {th }}$ parameter is packing related for four types of packing's. 
Role of RFID to minimize reverse logistics: A case study perspective

Table 4 Input and Output parameters to monitor the product status

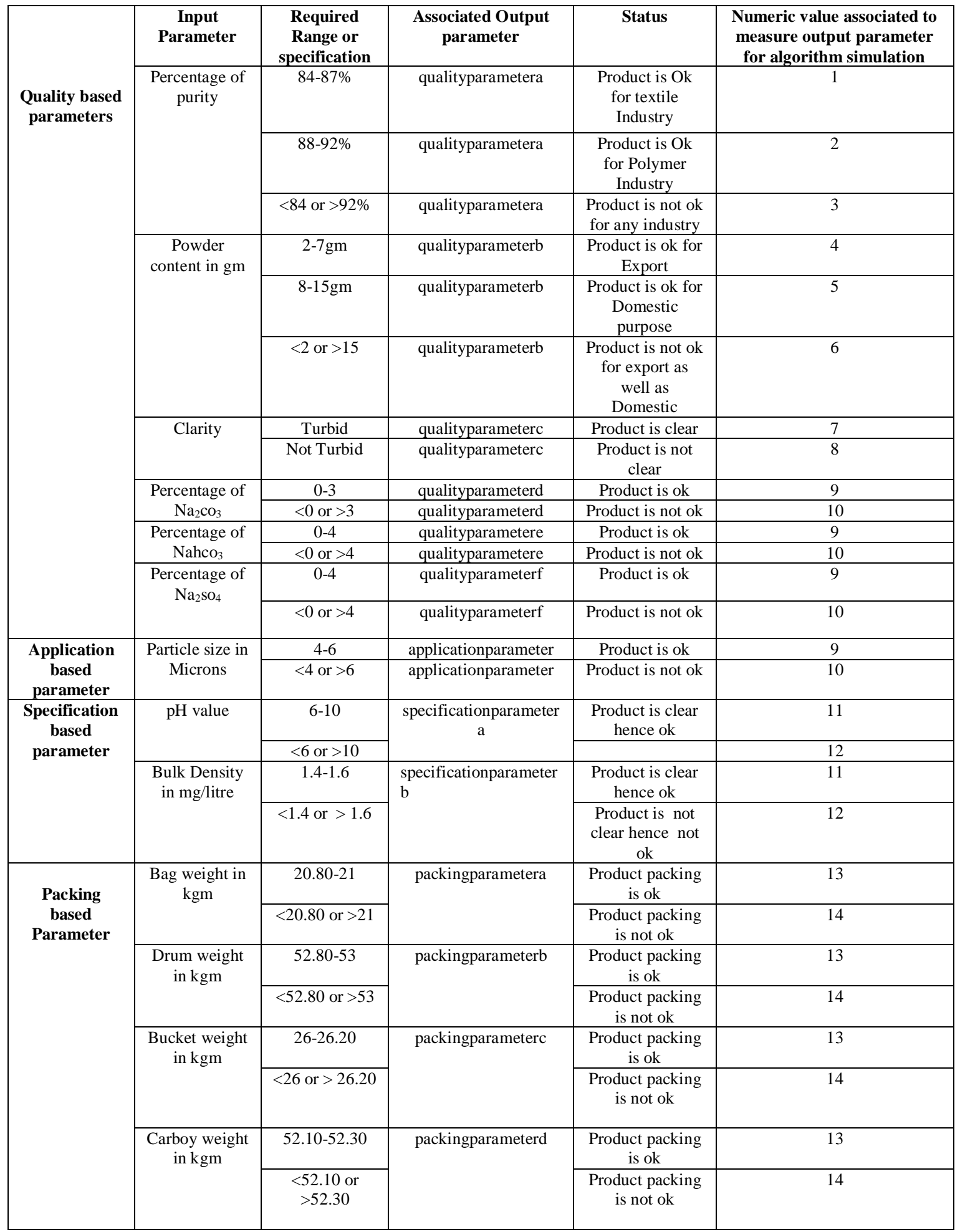




\section{Proposed Algorithm}

The proposed algorithm shows how to monitor ongoing process through RFID.

Figure 1 shows flow chart for the same.

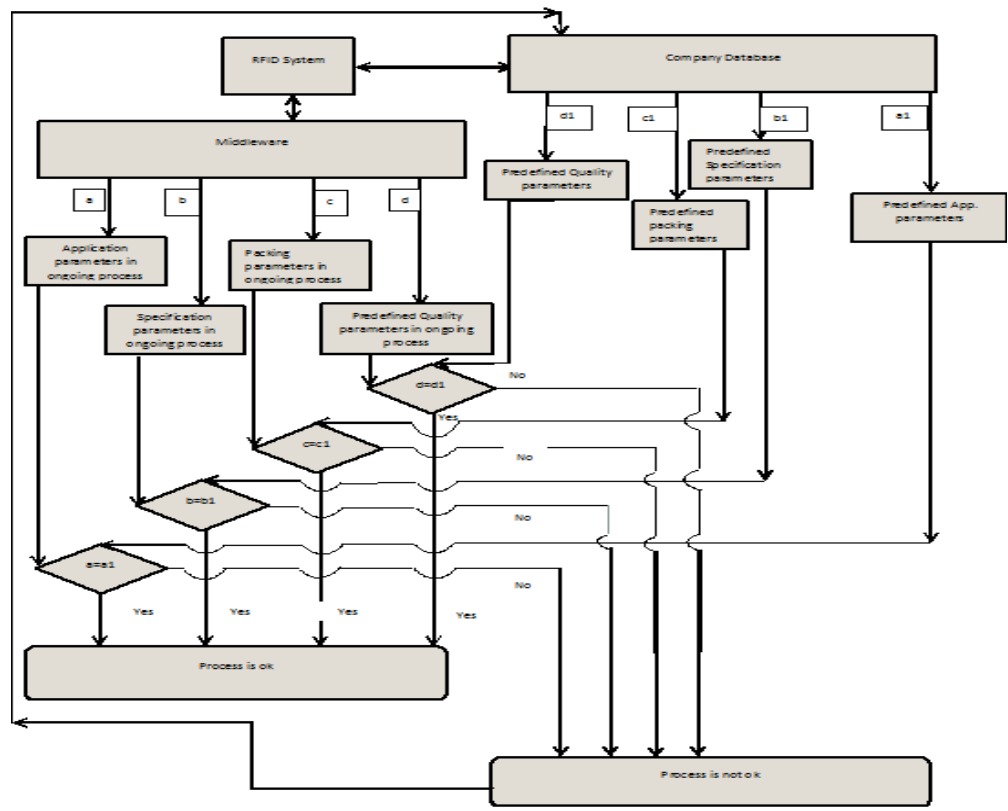

Fig 1 Flow chart of process

\section{Performance analysis}

Performance analysis has been done in two ways firstly the statistical analysis, to analyze the mean difference between the defects detected and complaints received are significant at $95 \%$ confidence interval around the mean, secondly the MATLAB 7.0 software has been used to generate the results and graphs for the proposed Algorithm to get the overview of RFID working environment.

\subsection{Statistical analysis}

Standard deviation and mean has been calculated at $95 \%$ confidence interval for both, defects detected and complaints received. (For calculations author has used the combined value for $\mathrm{D}, \mathrm{Bu}, \mathrm{C}$ and $\mathrm{B}$ by adding them for different category of complaints received and defects detected).Table- 5 and Table- 6 shows the statistical results through data analysis .

Table- 5 mean and standard deviation calculation for defects detected

\begin{tabular}{|c|c|c|c|c|c|c|c|c|c|c|c|c|c|c|c|c|}
\hline & & \multicolumn{6}{|c|}{ Defects detected } & & & & & \multicolumn{2}{|c|}{ std. deviation $\left.\mathbf{( s d}_{\mathbf{1}}\right)$} & $\boldsymbol{\mu}_{\mathbf{1}}$ & $\boldsymbol{\mu}_{\mathbf{2}} \mathbf{s d}_{\mathbf{1}}$ & $\boldsymbol{\mu}_{\mathbf{2}} \mathbf{s d}_{\mathbf{1}}$ \\
\hline $\mathbf{D}$ & 3 & 9 & 5 & 1 & 4 & 5 & 2 & 3 & 4 & 6 & 2 & 2.236067977 & 4 & 8.472136 & -0.47214 \\
\hline $\mathbf{B u}$ & 5 & 6 & 4 & 4 & 5 & 2 & 3 & 5 & 6 & 3 & 4 & 1.272077756 & 4.272727 & 6.816883 & 1.728572 \\
\hline C & 7 & 11 & 3 & 5 & 6 & 2 & 5 & 6 & 6 & 5 & 5 & 2.296241989 & 5.545455 & 10.13794 & 0.952971 \\
\hline B & 0 & 0 & 18 & 6 & 9 & 4 & 4 & 10 & 8 & 9 & 2 & 5.258758927 & 6.363636 & 16.88115 & -4.15388 \\
\hline
\end{tabular}

Table- 6 mean and standard deviation calculation for complaints received

\begin{tabular}{|l|l|l|l|l|l|l|l|l|l|l|l|l|l|l|l|l|}
\hline & & \multicolumn{6}{|c|}{ Complaints received from customers } & & & & & std.deviation $\left(\mathbf{s d}_{2}\right)$ & $\boldsymbol{\mu}_{\mathbf{2}}$ & $\boldsymbol{\mu + 2}_{\mathbf{2}} \mathbf{s d}_{\mathbf{2}}$ & $\boldsymbol{\mu}_{-2} \mathbf{s d}_{\mathbf{2}}$ \\
\hline D & 6 & 6 & 5 & 6 & 6 & 4 & 2 & 3 & 6 & 3 & 2 & 1.694912173 & 4.454545 & 7.84437 & 1.064721 \\
\hline Bu & 10 & 8 & 8 & 10 & 4 & 5 & 3 & 4 & 6 & 3 & 5 & 2.607680962 & 6 & 11.21536 & 0.784638 \\
\hline C & 10 & 10 & 4 & 7 & 10 & 1 & 7 & 8 & 4 & 5 & 5 & 2.944949452 & 6.454545 & 12.34444 & 0.564647 \\
\hline B & 0 & 0 & 23 & 18 & 11 & 8 & 7 & 10 & 8 & 6 & 3 & 7.019453488 & 8.545455 & 22.58436 & -5.49345 \\
\hline
\end{tabular}

From the statistical analysis shows the significant difference between the mean values for complaints received and defects detected. Difference of mean has been taken as $\Delta \mu=\mu_{2}-\mu_{1}$. This difference has been shown in graphical manner in fig. 2, fig. 3, fig. 4, fig. 5 respectively for drum, carboy, bag and bucket. 


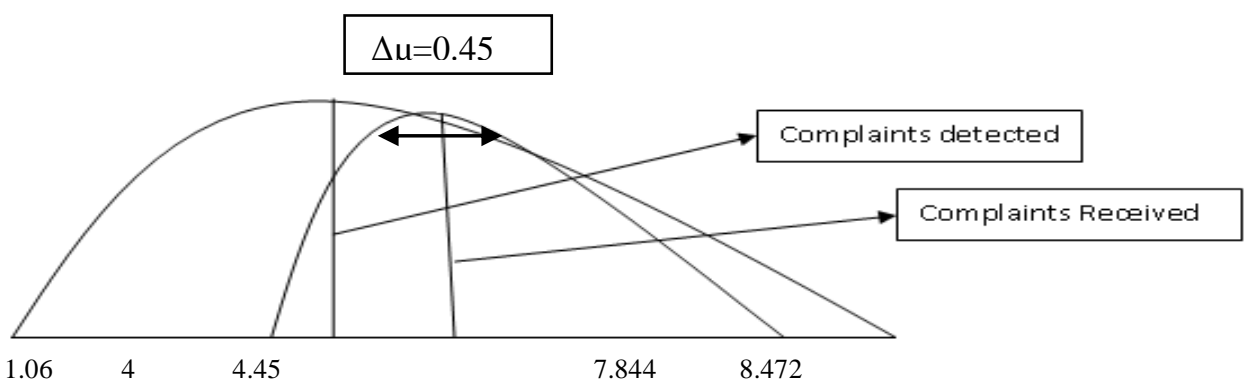

Fig. 2 Mean difference for drums between complaints received and defects detected

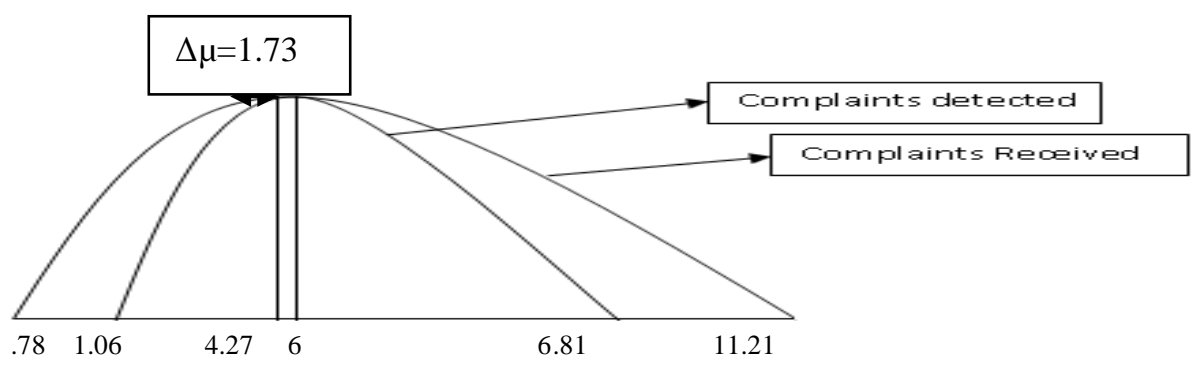

Fig. 3 Mean difference for Bucket between complaints received and defects detected

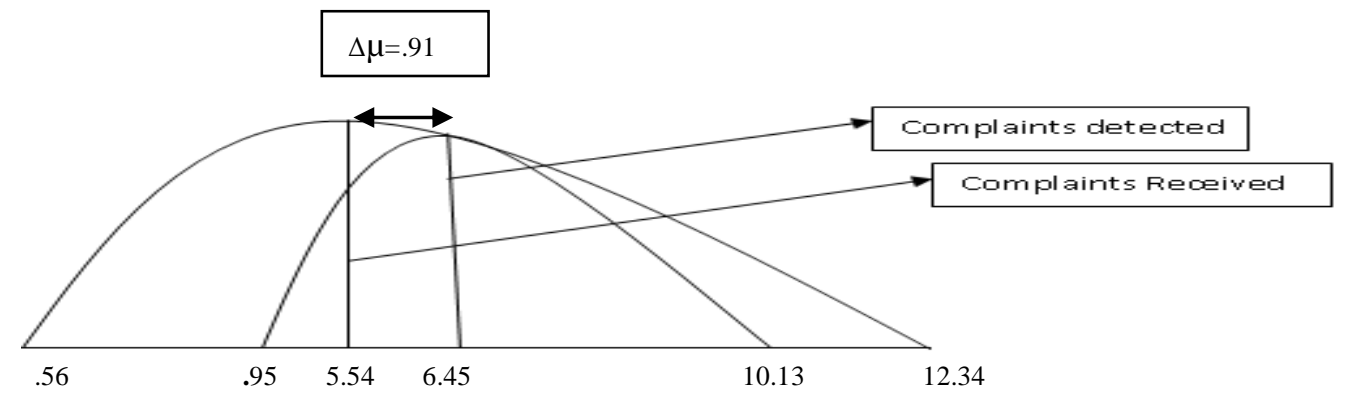

Fig. 4 Mean difference for Carboy between complaints received and defects detected

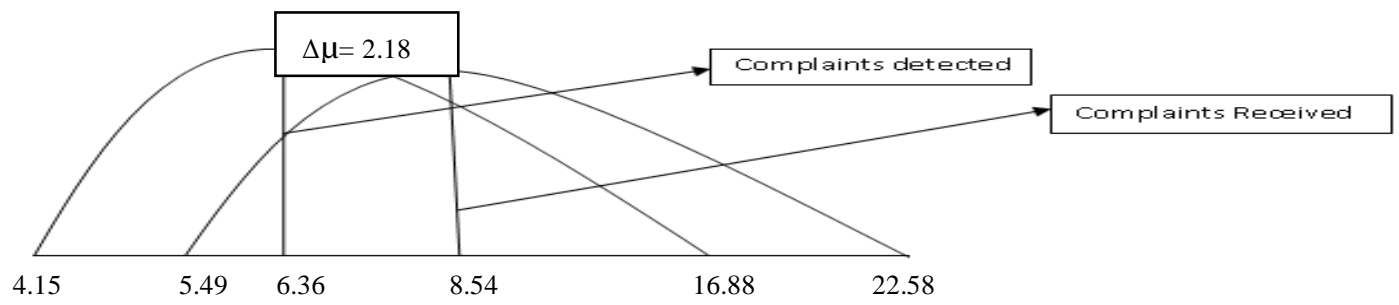

Fig. 5 Mean difference for Bag between complaints received and defects detected

From the above graphs it can be analyzed there is major mean difference or gap between the defects detected and complaints received for $\mathrm{D}, \mathrm{Bu}, \mathrm{C}$, and $\mathrm{B}$ as follows $.45,1.73, .91$, and 2.18 respectively. Results from table 7 shows that the probability of a sample not being chosen in a batch for $\mathrm{D}, \mathrm{Bu}$. C and $\mathrm{B}$ is higher as $93.024 \%, 94.88 \%, 93.41 \%$ and $96.48 \%$ respectively. Table -7 shows the individual probability of a sample being chosen in a batch size.

Table 7 Table describing the probability of a sample being chosen or not

\begin{tabular}{|l|l|c|c|}
\hline Batch size & $\begin{array}{l}\text { probability of a sample being chosen } \\
\text { in a batch p=1-((1-1/N)^n) }\end{array}$ & $\begin{array}{l}\text { probability of a sample } \\
\text { not being chosen in a } \\
\text { batch }\end{array}$ & $\begin{array}{l}\text { Number of Samples } \\
\text { being chosen((n= } \sqrt{\text { Batch size)+1) }}\end{array}$ \\
\hline $\mathrm{D} 222_{50 \mathrm{~kg}}$ & $.06976(6.976 \%)$ & $.93024(93 \%)$ & 16 \\
\hline $\mathrm{Bu} 400_{25 \mathrm{~kg}}$ & $.05120(5.120 \%)$ & $.9488(94 \%)$ & 21 \\
\hline $\mathrm{C}_{250_{50 \mathrm{~kg}}}$ & $.06586(6.586 \%)$ & $.93414(93 \%)$ & 17 \\
\hline $\mathrm{B} 800_{20 \mathrm{~kg}}$ & $.03562(3.562 \%)$ & $.96438(96 \%)$ & 29 \\
\hline
\end{tabular}

$* \mathbf{D 2 2 2}_{50 \mathrm{~kg}}=50 \mathrm{~kg}$ packing of drums with batch size of 222 drums

*Bu400 ${ }_{25 \mathrm{~kg}}=25 \mathrm{~kg}$ packing of buckets with batch size of 400 drums

* $\mathbf{C 2 5 0}_{\mathbf{5 0 k}}=50 \mathrm{~kg}$ packing of carboys with batch size of 250 carboys

$* \mathbf{B 8 0 0}_{20 \mathrm{~kg}}=20 \mathrm{~kg}$ packing of buckets with batch size of 800 drums 


\subsection{Simulation Results}

MATLAB 7.0 has been chosen for the simulation of algorithm, fig. 6 and fig. 7 are the reports generated through simulation of algorithm which shows the RFID environment working, giving the status ongoing process. Input parameters re entered and output parameters are generated accordingly as per the specifications mentioned in Table-4.First report of the MATLAB shows that how the inputs are reported in the middleware of RFID (software which extracts the useful information from RFID readers implemented in the application) and then the outputs shows the status of the product in terms of whether it has to be accepted or not which can be stored in company database. MATLAB report-2 is another report where we have taken a example which have some predefined specification such as follows in Table-8, which is entered as inputs in algorithms and output is generated according to the specifications by associating the numeric value to the output parameter mentioned in Table-4.

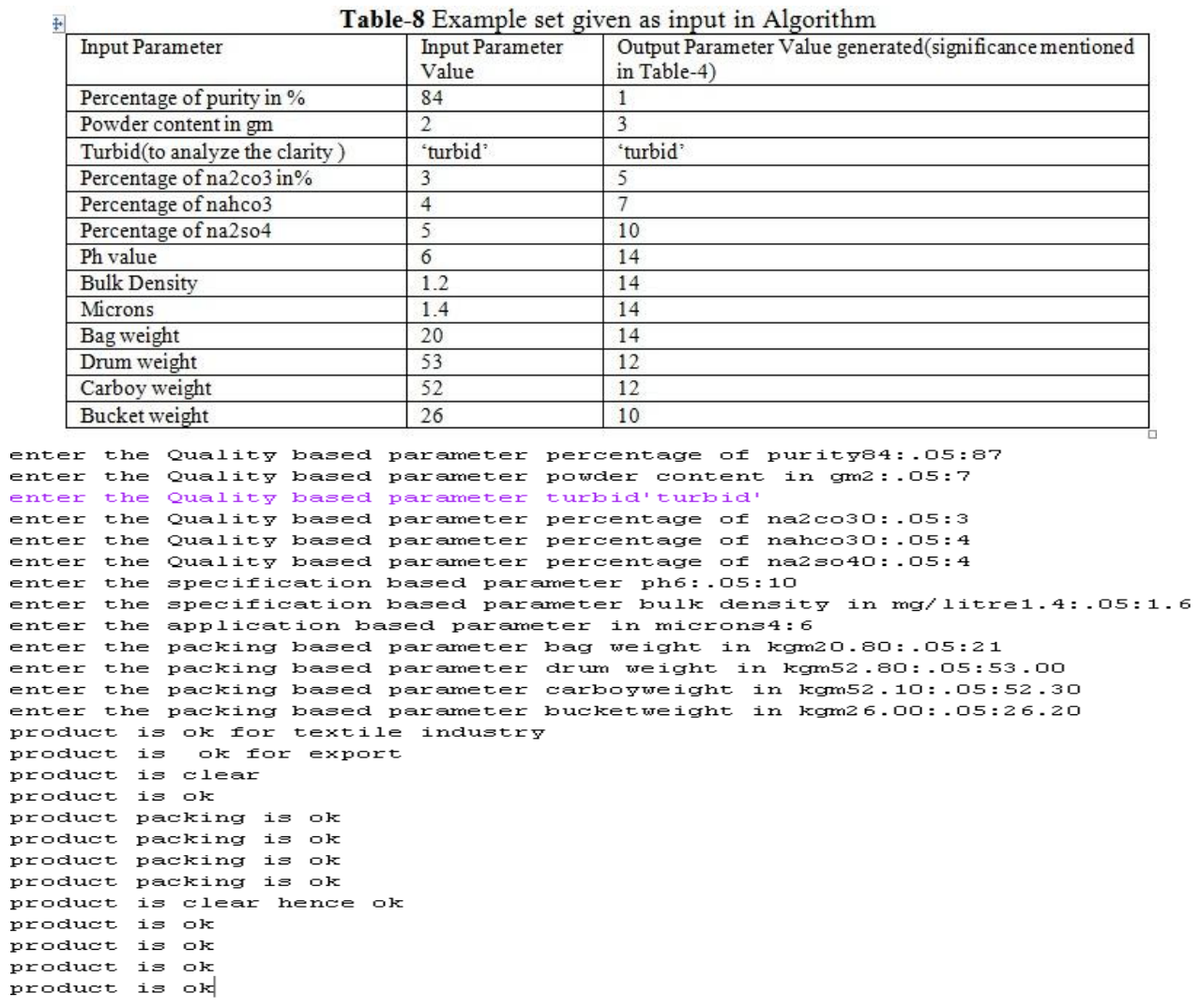

Fig. 6 Report 1 generated as per the specified range

enter the Quality based parameter percentage of purity84 enter the Quality based parameter powder content in gm2 enter the Quality based parameter turbid 'turbid' enter the Quality based parameter percentage of na2co33 enter the Quality based parameter percentage of nahco34 enter the Quality based parameter percentage of na2so45 enter the specification based parameter ph6 enter the specification based parameter bulk density in $\mathrm{mg} / \mathrm{litre} 1.2$ enter the application based parameter in microns1.4 enter the packing based parameter bag weight in $\mathrm{kgm} 20$ enter the packing based parameter drum weight in $\mathrm{kgm} 53$ enter the packing based parameter carboy weight in kgm52 enter the packing based parameter bucket weight in $\mathrm{kgm} 26$

output parameters $=$

\begin{tabular}{|l|r|r|r|r|r|r|r|r|r|r|r|r|r|}
\hline 1 & 3 & 5 & 7 & 10 & 14 & 14 & 14 & 14 & 12 & 12 & 10 & 10 & 10 \\
\hline
\end{tabular}

Fig.7 MATLAB report 2 ( by asssociating theoutput parameter to numeric value mentioned above in table 4)

In fig. 8 a graph is shown for the packing parameter vs. packing weight .In this graph the highlighted parameters are the packing weights within accepted range showing the output as thirteen (13) while others are not accepted showing fourteen (14) as output in numeric for different types of packing (carboy, bag, drum, and bucket). 


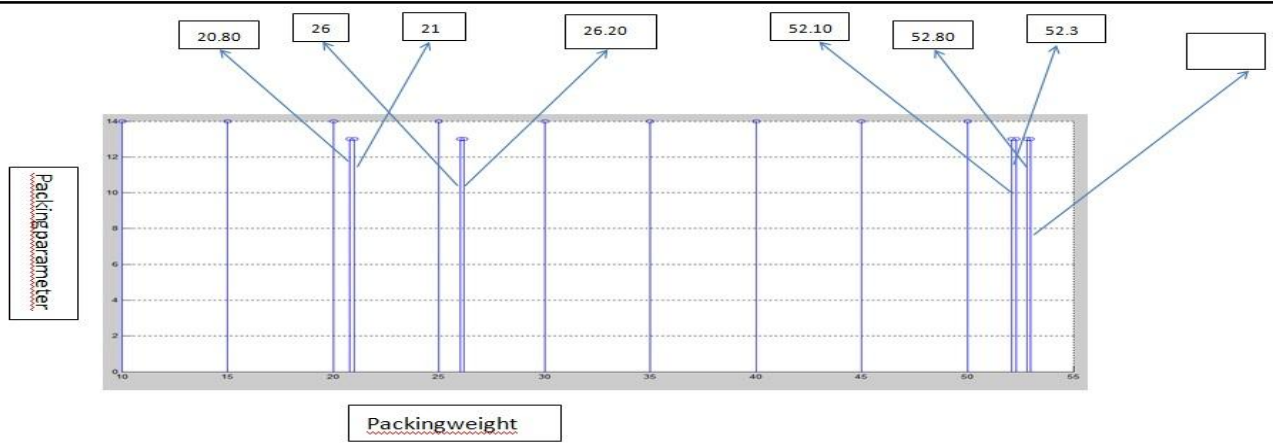

Fig.8 Packingparameter vs.Packingweight

Output parameter is generated indicating whether the input parameter is accepted or not as, 13 and 14 in numeric value respectively. Similarly other graphs can also be obtained using the values mentioned in table 4 for judging the process simulation in MATLAB. In this way a basic RFID working environment can be understood for process monitoring and gaining the useful knowledge for further analysis.

\section{Conclusion}

Through the statistical analysis it can be said that there is major gap between the defects detected and the complaints received and through RFID implementation this gap can be minimized. Through the simulation of proposed algorithm it can be said that RFID implementation gives us the real time analysis of the ongoing process in which specification parameters can be monitored and if defect is detected then this information is recorded in company database and finally this information could be helpful for further action to be taken in reverse logistics flow.

\section{Limitations and future scope}

In this paper the author has only considered customer complaint as part of reverse logistics. The other aspects of reverse logistics can be considered, viz. remanufacturing, recycling and reverse logistics for re-usage of products. The supply chain contracts like 'Buy back contract', 'pay back contract' can be considered for future studies.

\section{References}

[1] Dee, B., Karapetrovic, S. and Webb, K. As easy as 10001, 2, 3, Quality Progress, 36(6), (2004).

[2] Dey, P., Hariharan, S. and Ho, W. Innovation in healthcare services: a customer-focused approach. International Journal of Innovation and Learning, 6(4), 2009, 387-405.

[3] Fornell,C and Wernerfelt,B. A Model for Customer Complaint Management. Marketing Science, 7(3), 1988, $287-298$.

[4] Ovenden, A. Keep your customers happy and your competition will slowly fade away, The TQM Magazine, 7(1), 1995, 46-59.

[5] Lieckens, K., \&Vandaele, N. Reverse logistics network design with stochastic logistics systems: case studies approach. International Journal of Production Research, 48(5), 2007, 1361-1380.

[6] Jun Ji, G. Reverse Logistics Operation Management Based on Virtual Enterprises and Complaint Service Management. Journal of Service Science. \& Management.1, 2008, 51-65.

[7] S. Dowlatshahi . A cost-benefit analysis for the design and implementation of reverse lead times. Computers and Operations Research, 34(2), 2010, 395-416.

[8] Ginter, P. M., \& Starling, J. M. Reverse Distribution Channels for Recycling. California Management Review, $20(3), 1978,72-82$.

[9] Stock, J.K. Reverse logistics, white paper, council of logistics management, Oak Brook, IL (1992).

[10] Lee, L. S., Fiedler, K. D. and Smith, J. S. Radio frequency identification (RFID) Implementation in the service sector: A cu stomerfacing diffusion model. International Journal of Production Economics, 112(2), 2008, 587-600.

[11] McFarlane, D., Sarma, S., Chirn, J., Wong, C., Ashton, K. Auto ID systems and intelligent manufacturing control. Engineering Applications of Artificial Intelligence, 16(4), (2003), 365-376.

[12] Chan, F. T. S., \& Chan, H. K. A survey on reverse logistics system of mobile phone industry in Hong Kong. Management Decision, 46(5), 2008, 702-708.

[13] De Brito, M. and Dekker, R. A framework for reverse logistics. In Reverse Logistics. Quantitative Models for Closed-Loop Supply Chains, 2004, 3-27

[14] Chung, C.-Jen, \& Wee, H.-Ming. Green-component life-cycle value on design and reverse manufacturing in semi-closed supply chain. International Journal of Production Economics, 113(2), 2008, 528-545.

[15] Srivastava, S.K. \& R.K. Srivastava. Managing product returns for reverse logistics. International Journal of Physical Distribution \& Logistics Management. 36 (7), 2006, 524-546.

[16] Kotler, P. Marketing Management (9th ed., Englewood Cliffs, NJ: Prentice-Hall, 1997)

[17] Lambert D.M. \&Burduroglu R. Measuring and selling the value of logistics. The International Journal of Logistics Management, 2000, 1-17.

[18] Stock, J.R., Speh, T.W. \& Shear, H.W. Many happy (product) returns. Harvard Business Review, 80 (7), $2002,16-17$.

[19] Lee, C. K. M., \& Chan, T. M. (2009). Development of RFID-based Reverse Logistics System. Expert Systems with Applications, 36(5), 2009, 9299-9307.

[20] Li, S., Visich, J.K., Khumawala, B.M., Zhang, C., Radio frequency identification (Prentice-Hall, 2006)

[21] García, A., Chang, Y., Abarca, A., \& Oh, C. RFID enhanced MAS for warehouse management. International Journal of Logistics Research and Applications, 10(2), 2007, 97-107.

[22] Gaukler G., Seifert S., Hausman (2007) Item-level RFID in the retail supply chain. Production and Operations Management, 16(1), 2007, 65-76. 